\title{
Flexible Work Arrangements and Their Impact on the Employee Performance of Egyptian Private University Employees: (A Case Study on the Arab Academy for Science, Technology, and Maritime Transport)
}

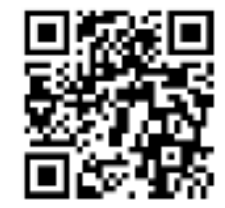

\author{
Mohamed Eshak ${ }^{1}$, Prof. Mohamed Wahba Mohamed Hassan², Dr. Abdel Nasser Ghanem ${ }^{3}$ \\ 1,2,3 The Arab Academy for Science, Technology, and Maritime Transport, Alexandria, Egypt.
}

\begin{abstract}
This study aimed to analyse the impact of flexible work arrangements on the employee performance of employees in private Egyptian universities in Alexandria, mediated by work-life balance (applied to the Arab Academy for Science, Technology, and Maritime Transport). institutions to retain talented people, raise the efficiency of employee performance, and thus raise the efficiency of institutional performance and competitive capabilities of organizations. The researcher used the descriptive analytical method and the questionnaire as a tool for data collection, to measure the impact of flexible work arrangements (focusing on reducing working hours, benefits provided to employees, work policies towards parenting) on the work-life balance, and the extent of the impact of all this on raising the efficiency of employees' employee performance. A stratified random sample of 423 employees was used, and the data collected was analysed using SPSS and AMOS statistical software. The findings revealed a positive relationship between flexible work arrangements (reduced working hours, benefits provided to employees, and work policies toward parenting) and employee performance, as well as a positive relationship between flexible work arrangements and work-life balance, as well as a positive relationship between work-life balance and employee performance, and the researcher recommends implementing such policies. The recommendations also include the need to review current labour laws before legislators, and update them in line with contemporary technological development and the requirement to achieve a balance between the requirements of life and work. This study also recommends the adoption of reducing working hours as one of the flexible work policies offered by organisations to employees. The study concludes that flexible work arrangements and programmes are in fact a competitive tool that organisations can use to increase loyalty, improve performance, achieve commitment and job satisfaction, which enhances the organization's productivity.
\end{abstract}

KEYWORDS- FWAs (flexible work arrangements), reducing working hours, WLB (work-life balance), EP (Employee performance)

\section{INTRODUCTION}

The business world is dominated in the current era by a group of strong trends such as globalization, digitization, and the increasing importance of intangible assets, and then organizations and employees need more flexibility and adaptability in support of a culture of productivity and for more progress and growth, which are the slogans raised by the most effective and successful institutions in This is our time. However, with the recent Covid-19 disease, organizations were suddenly forced to change their practice and thus find new solutions to challenges arisen in many areas of their operations Carneval and Hatak (2020), many organizations offer flexible working hours to employees because of benefits of flexibility for both employees and organizations. Work-life balance has shown its importance since the past decades, it has already been found that work-life balance is a major factor to improve employee's productivity which impact the overall performance of organizations positively Semlali and Hassi (2016). SOPs, organizational environment, attitude of employers, and support of supervisors and managers are vital factors affecting work-life balance Haider and Azmi (2019). Ghanem (2010) study uncovered the unawareness among individuals and organizations in the Egyptian society of the importance of work -family balance compared with Western societies. Such findings highlight the importance of this study and the urgent need to change the working hours convention stipulates the working hours should not exceed 8 hours/day and 48 hours/week (with some exceptions). However, the definition of long working hours in some countries depends on national regulations, as many countries define standard working hours as 35-40 hours/week and 41 hours/overtime work week (Convention No. 1 of the International Labor Organization), which was adopted by the ILO General Conference at its first session in October (1919 AD), and its implementation began in June 1921 AD, and was renewed at the meeting of the International Labor Council in 


\section{Flexible Work Arrangements and Their Impact on the Employee Performance of Egyptian Private University}

Employees: (A Case Study on the Arab Academy for Science, Technology, and Maritime Transport)

its forty-sixth session June 1962 AD by Recommendation No. (116), Geneva Conference in 1962 AD. International Labor Organization (2017); University of Minnesota (2021).

The dates of these agreements indicate the need to search for more suitable arrangements for this era, especially with greater dependence on technology nowadays. Reducing the number of working hours has become an urgent matter. Therefore, this study had to address the impact of flexible work arrangements, and the resulted work-life balance on the employees' performance in private Egyptian universities, which is discussed in this study.

\section{LITERATURE REVIEW}

\section{Relationship between flexible work arrangements and Employee performance}

It was shown in the study of Govender et al. (2018) that performance and flexible working arrangements have a strong positive relationship, and the study found that flexible working arrangements enhanced employee retention and job satisfaction, which led to increased productivity. There is a significant and positive relationship between flexible working arrangements and performance in the workplace, as well as education, age, wages, quality of manager-employee relationships, years of experience, the area of the market in which the workplace is operated, and competition are important factors and positively correlate with the tendency to implement flexible working arrangements. Giovanis (2018). There is a positive relationship between the dimensions of the quality of work life and the level of organizational commitment, and it was found that the variables affecting organizational commitment are (material work conditions, work-life balance, wages and rewards, security, and job stability) Al-Biyari (2018). The roles of work systems and procedures for human resources personnel contribute significantly to achieving outstanding performance for individuals. Kharshi (2019).

he more effort there is and the development of flexible policies for human resource management, the more it motivates employees to increase their productivity, improve the quality of their outputs, control time management in fulfilling work and life commitments, increase focus, decrease health care costs and stress-related diseases, and increase worker loyalty, The organization is distinguished by providing the best services and benefits to its employees, making it an attractive environment for customers and employees, which contributes to increasing Employee performance. The purpose of Bear (2017) study was to study the relationship between flexible working arrangements and work-family conflict and examined self-control as a moderator between the relationship between flexible working arrangements and employees' experience of work-family conflict in a large technology company in San Francisco. in the United States of America. The method used in this study is the descriptive analytical method, and the number of participants included 172 employees, and the tool used in the study is the questionnaire by sending it to them via e-mail, and the response rate was $28.6 \%$. Participants with missing data were excluded, which led to the arrival of the final sample. To 149 participants from the Bay Area chapter.

The results showed a positive relationship between the availability of flexible working arrangements, dedication, and sincerity, as well as the use of flexible working arrangements. And the study of Hsu et al. (2019) studied the links between the effect of long working hours and the balance between work and private life and job satisfaction mediated by occupational stress, and tested whether controlling working time helps mitigate the effects of long working hours and occupational stress?

This study used the descriptive analytical method, and the tool used for measurement is the questionnaire, and the study population consisted of (369) individuals. The results revealed that there is a significant correlation between long working hours, professional tension, and work-life balance, as well as a relationship between occupational stress and work-life balance. and job satisfaction, and the most important recommendations are the need to review labor laws to prevent excessive working hours and enhance working time flexibility.

Based on the previous studies, the researcher can develop the first hypothesis, which is: H1: There is a statistically significant effect between flexible work arrangements and the Employee performance. for employees in Egyptian private universities.

\section{The relationship between flexible work arrangements (the independent variable), work-life balance (the mediating variable)}

Giovanis (2018) stated that flexible working arrangements provide employees with job control and autonomy, improve work-life balance, and lead to increased productivity. The researchers explained how employees who view a supportive work culture within their organisational culture are more likely to experience less work-family conflicts. choo et al. (2016). However, there is more evidence that flexibility provides work-life balance, particularly during parenting, work-life balance, and gender equality, that the marital status of an employee working in an organisation is important, and that telecommuting and flexible working do not benefit employees who have a partner and/or a child, but only for individuals, according to Chung and Lippe (2018). Studying Deepika and Elango (2020) This study aimed to provide a socio-economic overview and social support for female employees in the hospitality industry in Chennai, India. The study is based on the descriptive analytical method. The tool used in the study is a questionnaire. A number of (130) questionnaires were distributed. The results of the study show that more than a third of the respondents (39.2\%) suffer from a lack of work-life balance, and that less than a third of the respondents (26.0\%) suffer from poor work. The study by Martínez-León et al. (2019) has the purpose of investigating the impact of work-life balance practises on the financial outcomes 


\section{Flexible Work Arrangements and Their Impact on the Employee Performance of Egyptian Private University}

Employees: (A Case Study on the Arab Academy for Science, Technology, and Maritime Transport)

of Spanish auditing SMEs. Using survey data from 148 Spanish audit firms, a group of 535 Spanish SME audit firms was identified from a database, Sistema de Análisis de Balances Ibéricos (SABI) Data A survey questionnaire was sent by phone or email to 148 (professional) references from different companies, and from the study findings, availability of WLB practises is fundamental not only to policy makers and society, but also to organisational culture and human resource management practices. The study recommends that senior managers should enhance certain WLB (time-reduced and flexible work practices) to enhance the financial results of SME audit firms. As for the Al-Buhairi study (2018), it aimed to build a model that defines the framework that describes and analyses the impact of applying work-life balance strategies on administrative performance, and the study sample was (314). The study found that there is an imbalance between work and life, especially for women without men, and that the application of work-life balance strategies leads to improving the level of effectiveness of the administrative performance of managers in Egyptian government institutions. (Teleworking - Part-time work - Job sharing - Stressed work week - Providing health care to managers and their families - Giving managers childcare and parental leave).

Based on the previous studies, the researcher can develop the first hypothesis, which is:H2: There is a statistically significant effect between flexible work arrangements and the working life balance.

\section{The relationship between work-life balance and Employee performance}

Bataineh (2019) study aimed to study the impact of life-work balance and happiness at work on Employee performance and concluded that work-life balance and happiness positively and significantly affect employee performance. Obiageli's (2015) study examined work-life balance and employee performance to determine the extent of the impact of leave on service provision, and concluded that it stimulates the employee's ability, and work-life balance is an important factor in increasing employee performance. The results of the study by Mendis and Weerakkody (2017) revealed that there is a significant positive relationship and impact of work-life balance on employee performance, as well as the role of family and demographics play an important role as controlling variables to maintain an appropriate work-life balance in organizations.

The study of Wong et al. (2020) When evaluating the relationship between work-life balance ranking and Employee performance and measuring it based on six perspectives including job motivation, employee attendance, employee recruitment, employee retention, organizational commitment, and productivity, the results showed a positive relationship between work-life balance ranking Life and organizational performance and the intermediate variables that influenced the relationship between work-life balance order and organizational performance are gender, sector and employee hierarchy. The Effect of Supervisor Support and Work-Life Balance on Employee Performance, Job Satisfaction, and Life Satisfaction Talukder (2018).

Successful implementation of flexible work arrangements can be a vital publicity tool for organisations, the principles of the organization and how they manage the business internally are extremely important Ko and Kim (2018). The benefits of flexible working arrangements for both employee and employer are clear, in terms of improved work-life balance and employee well-being, to higher rates of productivity and performance, research by CIPD (Char Ted Institute for Professional Development) revealed these benefits and was highlighted by Wells (2021). Flexible working is a common and respected practice around the world today, and flexible working practices are typically implemented to give employees a degree of choice about how much (operational flexibility), when (time flexibility) and where (location flexibility) they should work, helping them strike a balance Satisfactory between work and life as such, one would not expect implementing flexible work to intensify work.) Kelliher and Anderson (2010; Opatha (2009). As a result, there is a growing interest in implementing flexible work arrangements in organizations to help employees balance responsibilities Work and family Baeza et al. (2018).

Based on the previous studies, the researcher can develop the first hypothesis, which is: H3: There is a statistically significant effect between the work-life balance and the employee performance.

$I V$. Work-life balance mediates the relationship between flexible work arrangements and employee performance.

The study De Sivatte et al. (2015) examined the relationship between working life and organizational productivity and determining whether it was mediated by working life programs. From two databases, and other archival data published in three international surveys, hypotheses were tested using path analyses, and the data revealed that working life culture has no direct impact on work productivity, but it has an indirect effect on it, through the availability of life programs The study found the importance of promoting a culture of conducive work life and providing programs for work-life balance because it enhances work productivity.

A study Taşdelen-Karçkay and Bakalım (2017) indicated that the work-life balance scale as a mediating variable aims to develop a measure of work-life balance for Turkish women and men. The sample was (274), and the second objective was to investigate the mediating effect of work-life balance between work-family conflict, work-family conflict, and life satisfaction, in Study 2 and the sample was (356). All studies indicated that the work-life balance scale It was valid and reliable Structural equation models supported the indirect effects of work-family conflict and work-family conflict on life satisfaction through work-life balance. Ajayaghosh and Santhosh (2020) This study aims to understand what drives work life balance and how WLB affects employee performance in selected commercial banks from the central region of Kerala, with the aim of analyzing the presence of WLB 
Flexible Work Arrangements and Their Impact on the Employee Performance of Egyptian Private University Employees: (A Case Study on the Arab Academy for Science, Technology, and Maritime Transport)

enablers on employee performance in commercial banks as well as whether WLB performance always indicates satisfactory performance and thus can be considered as a tool for predicting employee performance.

Based on the previous studies, the researcher can develop the first hypothesis, which is: H4: work-life balance mediates the relationship between flexible work arrangements and the employee performance.

\section{RESEARCH METHODOLOGY}

The researcher used the quantitative method. The research studied and reviewed the literature reviews and analyzed them to reach a comprehensive theoretical framework and accurate knowledge of the subject of the study in describing flexible work arrangements and their impact on the Employee performance of employees. Averages, percentages, and statistical tests were used as one of the analysis tools, and this approach is concerned with collecting data through measuring tools that are developed to have honesty and reliability, then they are applied to the sample population, and the results are drawn and evaluated, and the following hypotheses are tested:

Independent variable: The theoretical framework explains the entire study. For flexible work arrangements as an independent variable, there are many programs and policies that must be considered, but in this study, we focus on three variables: (reduce working hours - benefits provided to employees - work policies towards parenting).

Dependent variable: It is the Employee performance.

Mediator variable: work-life balance.

The controlling variable (moderator): It is represented in the demographic factors (gender - age - marital status - educational qualification - number of family members - number of years of experience).

\section{I. conceptual framework}

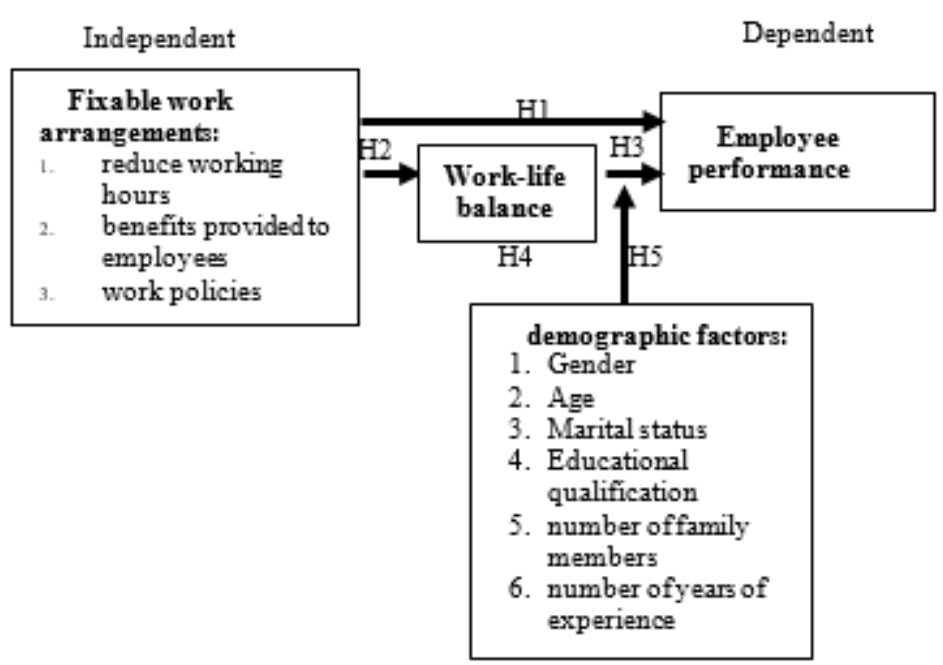

Figure 1: Research Framework

From the above framework, the research hypotheses can be developed as following:

H1: There is a statistically significant effect between flexible work arrangements and the Employee performance. for employees in Egyptian private universities. Three sub-hypotheses emerge from it as follows:

H1a: There is a statistically significant effect between reduce working hours and employee job performance.

H1b: There is a statistically significant effect between the benefits provided to employees and the job performance of employees.

H1c: There is a statistically significant effect between work policies towards parenting and employee job performance.

H2: There is a statistically significant effect between flexible work arrangements and the work-life balance.

H3: There is a statistically significant effect between the work-life balance and the employee performance.

H4: work-life balance mediates the relationship between flexible work arrangements and the employee performance.

H5: Demographic factors affect the relationship between work-life balance and the employee performance of employees in Egyptian private universities due to personal and occupational variables (age - gender - marital status - educational qualification number of family members - number of years of experience).

\section{Population of the Study}

consisted of faculty members at Arab Academy for Science, Technology and Maritime Transport, who form (4500) faculty members, at Egypt. 
Flexible Work Arrangements and Their Impact on the Employee Performance of Egyptian Private University Employees: (A Case Study on the Arab Academy for Science, Technology, and Maritime Transport)

\section{Sample of the study}

The study sample consisted of (423) faculty members who were randomly selected according to the different study variables.

\section{RESULTS AND FINDINGS}

In this section, the hypotheses under study are tested, they will do correlation analysis and you will analyze the regression between variables using multiple regression model and structural equation model. studying.

\section{Testing the First Hypothesis}

The researcher analyzes the structural equation model to show the impact of flexible work arrangements, including: (reduce working hours - benefits provided to employees - work policies towards parenting) on Employee performance. The following was found:

- There is no significant effect of reduce working hours on Employee performance, as the p-value is greater than 0.05 (p-value $=$ 0.973).

- There is a significant effect of the benefits provided to employees on Employee performance, as the p-value is less than 0.05 (pvalue $=0.000$ ). Also, the benefits offered to employees have a positive effect on employee performance, as the value of the rating factor is greater than zero (estimate $=0.215$ ).

- There is a significant effect of work policies towards parenting on Employee performance, as the p-value is less than 0.05 (pvalue $=0.000)$. Also, there is a positive effect of work policies towards parenting on Employee performance, as the value of the rating factor is greater than zero (estimate $=0.479$ ).

Moreover, the value of $\mathrm{R}$ Square is 0.428 , which means that $42.8 \%$ of the functionality can be explained by this model.

\section{Table 1: SEM analyses of FWAs on EP}

\begin{tabular}{|c|c|c|c|c|c|}
\hline $\begin{array}{c}\text { Dependent } \\
\text { Variable }\end{array}$ & $\begin{array}{c}\text { Independent } \\
\text { variable }\end{array}$ & Estimate & $\boldsymbol{p}$ & $\boldsymbol{R} 2$ \\
\hline $\begin{array}{c}\text { reduce working } \\
\text { hours }\end{array}$ & $<---$ & $\begin{array}{c}\text { Employee } \\
\text { performance }\end{array}$ & -.002 & .973 & \multirow{2}{*}{0.428} \\
\hline $\begin{array}{c}\text { benefits provided to } \\
\text { employees }\end{array}$ & $<---$ & $\begin{array}{c}\text { Employee } \\
\text { performance }\end{array}$ & .215 & $* * *$ \\
\hline $\begin{array}{c}\text { Work policies } \\
\text { towards parenting }\end{array}$ & $<---$ & $\begin{array}{c}\text { Employee } \\
\text { performance }\end{array}$ & .479 & $* * *$ & \\
\hline
\end{tabular}

It appears from Table 2 that the results are statistically significant, and the results indicated that the adjusted (chi) 2 statistic or weighted with degrees of freedom is 3.987, in addition to the Goodness of fit index of 0.900 and the Adjusted Goodness of Fit Index 0.859, and the Comparative fit index is 0.936, which are acceptable indicators; Because it is suitable for comparing the quality of the scales with the difference in sample size from one study to another. The square root of the Residual Mean Square error - RMSEA is 0.084 , which is the value that expresses the number of errors in the model that cannot be explained, and it is an acceptable value because it is less than $10 \%$.

Table 2: Indicator of the SEM of FWAs on EP

\begin{tabular}{|l|l|l|l|l|}
\hline CMIN/DF & GFI & AGFI & CFI & RMSEA \\
\hline 3.326 & 0.894 & 0.861 & 0.936 & 0.074 \\
\hline
\end{tabular}

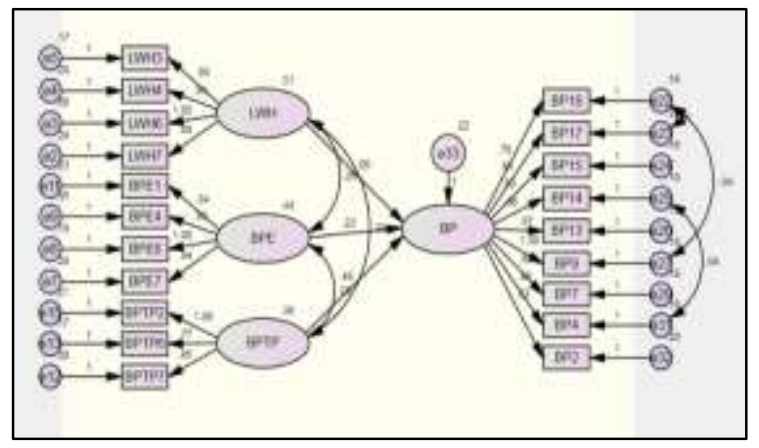

Figure 1: SEM of FWAs arrangements on EP 
Flexible Work Arrangements and Their Impact on the Employee Performance of Egyptian Private University Employees: (A Case Study on the Arab Academy for Science, Technology, and Maritime Transport)

Therefore, based on the previous results, H1: "there is a statistically significant effect between flexible work arrangements and the Employee performance of employees in Egyptian private universities" is fully acceptable.

\section{Testing the second Hypothesis}

Table 3 shows that the researcher analyzed the structural equation model to show the impact of flexible work policies, including: (low working hours - benefits provided to employees - work policies towards parenting) on life and work balance. The following was found:

- There is no significant effect of low working hours on work-life balance, $p$-value is greater than $0.05(\mathrm{p}$-value $=0.221)$.

- There is a significant effect of the benefits provided to employees on the work-life balance, as p-value is less than 0.05 ( $\mathrm{p}$ value $=0.000)$. Also, the benefits offered to employees have a positive effect on the work-life balance, as the value of the rating factor is greater than zero (estimate $=0.557$ ).

- There is no significant effect of work policies towards parenting on the work-life balance, as p-value is greater than 0.05 (pvalue $=0.835$ ).

Furthermore, the value of R Square is 0.416 , which means that $41.6 \%$ of the life-work balance can be explained by this model.

Table 3: SEM between FWAs on WLB

\begin{tabular}{|c|c|c|c|c|c|}
\hline variables & & & Estimate & $\boldsymbol{p}$ & $\boldsymbol{R} 2$ \\
\hline reduce working hours & $<---$ & Work-life balance & .069 & .221 & \\
\cline { 1 - 4 } benefits provided to employees & $<---$ & Work-life balance & .557 & $* * *$ & 0.416 \\
\cline { 1 - 4 } Work policies towards parenting & $<---$ & Work-life balance & .018 & .835 & \\
\hline
\end{tabular}

Table 4 shows the statistically significant results. The results indicated that the adjusted or weighted (chi) 2 statistic with degrees of freedom is 3.987, in addition to the Goodness of fit index of 0.900, and the Adjusted Goodness of Fit Index 0.859, Comparative fit index of 0.936, which are acceptable indicators, because it is suitable for comparing the quality of the scales with the difference in sample size from one study to another. The square root of the Residual Mean Square error - RMSEA is 0.084, which is the value that expresses the number of errors in the model that cannot be explained, and it is an acceptable value because it is less than $10 \%$.

Table 4: Indicator between SME on WLB on EP

\begin{tabular}{|l|l|l|l|l|}
\hline CMIN/DF & GFI & AGFI & CFI & RMSE \\
\hline 3.987 & 0.900 & 0.859 & 0.936 & 0.084 \\
\hline
\end{tabular}

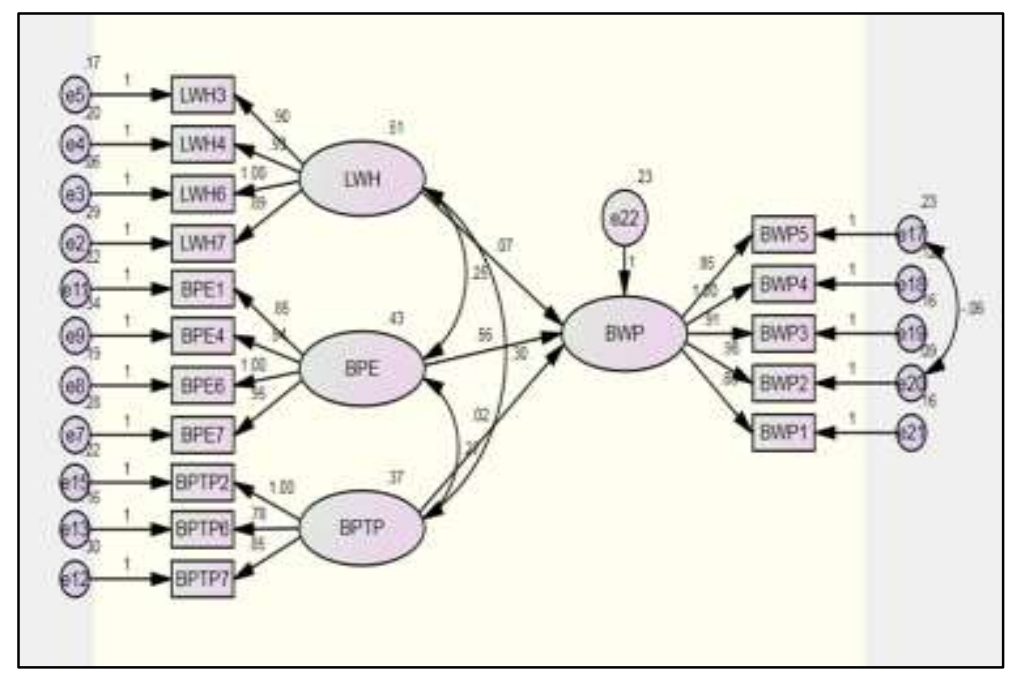

Figure 2: SEM between FWAs on WLB

Based on the previous results, H2: "there is a statistically significant effect between flexible work arrangements and the life and work balance of employees in Egyptian private universities" is fully acceptable. 
Flexible Work Arrangements and Their Impact on the Employee Performance of Egyptian Private University Employees: (A Case Study on the Arab Academy for Science, Technology, and Maritime Transport)

\section{Testing the third Hypothesis}

Table 5 shows that the researcher analyzed the structural equation model to show the impact of WLB on EP. The following was found:

- There is a significant effect of WLB EP, as P-value is less than 0.05 (P-value $=0.000)$. Also, there is a positive effect of worklife balance on Employee performance, as the value of the estimate factor is greater than zero (estimate $=0.648$ ). Moreover, the value of $\mathrm{R}$ Square is 0.437 , which means that $43.7 \%$ by this model.

Table 5: SEM between WLB on EP

\begin{tabular}{|c|c|c|c|c|c|}
\hline variables & & & Estimate & $\boldsymbol{p}$ & $\boldsymbol{R} 2$ \\
\hline Work-life balance & $<---$ & Employee performance & .648 & .000 & 0.437 \\
\hline
\end{tabular}

It appears from Table 6 that the results are statistically significant. The results indicated that the adjusted or weighted (chi)2 statistic with degrees of freedom is 3.165, in addition to the Goodness of fit index of 0.931, and the Adjusted Goodness of Fit Index 0.900, and a Comparative fit index of 0.965, which are acceptable indicators, because it is suitable for comparing the quality of the scales with the difference in sample size from one study to another. The square root of the Residual Mean Square error - RMSEA is 0.072 , which is the value that expresses the number of errors in the model that cannot be explained, and it is an acceptable value because it is less than $10 \%$.

Table 6: Indicator SEM between WLB on EP

\begin{tabular}{|l|l|l|l|l|}
\hline $\boldsymbol{C M I N / D F}$ & GFI & AGFI & $\boldsymbol{C F I}$ & $\boldsymbol{R M S E}$ \\
\hline 3.165 & 0.931 & 0.900 & 0.965 & 0.072 \\
\hline
\end{tabular}

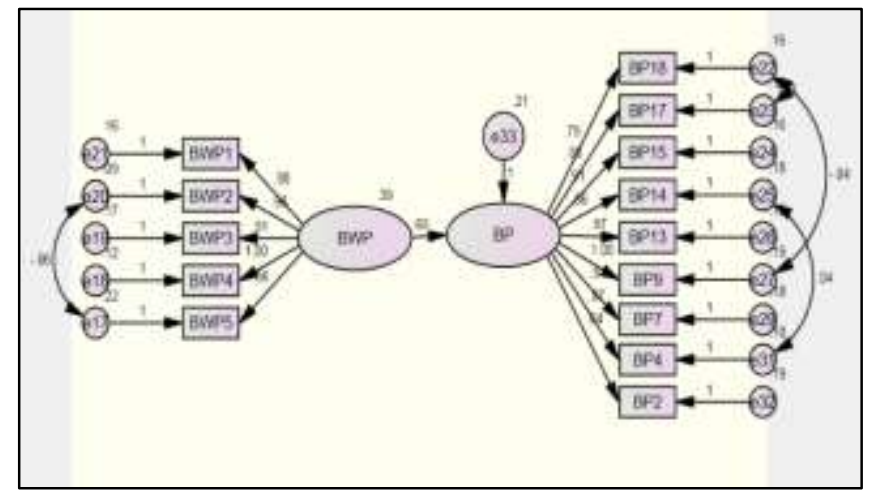

Figure 3: SEM between WLB on EP

Based on the previous results, H3: "there is a statistically significant effect between the work-life balance, and the Employee performance of employees in Egyptian private universities" is fully acceptable.

\section{Testing the Fourth Hypothesis}

Table 7 presents the results of the multiple regression test results for flexible work Arrangement and Employee performance. It was found that there is a significant relationship between FWAs and EP. It can be seen from Table 7 that there is a significant effect of WLB on EP. Therefore, WLB can play a mediating role between FWAs and EP, as there is a direct relationship between them and EP.

it can be noted that H4 : "WLB mediates the relationship between reduce working hours, work policies towards parenting and Employee performance" in a totality.

Whereas: "WLB mediates the relationship between benefits provided to employees and EP" in partially.

Table7: Analysis of the mediation role of WLB between FWAs and EP

\begin{tabular}{|c|c|c|c|c|c|c|}
\hline \multirow[t]{2}{*}{ Variables } & \multicolumn{2}{|c|}{ Unstandardized Coefficients } & \multirow{2}{*}{$\begin{array}{l}\text { Standardized } \\
\text { Coefficients }\end{array}$} & \multirow{2}{*}{$T$} & \multirow{2}{*}{ Sig. } & \multirow{2}{*}{$R 2$} \\
\hline & $\boldsymbol{B}$ & Std. Error & & & & \\
\hline (Constant) & 1.501 & .158 & & 9.483 & .000 & 0.363 \\
\hline
\end{tabular}


Flexible Work Arrangements and Their Impact on the Employee Performance of Egyptian Private University Employees: (A Case Study on the Arab Academy for Science, Technology, and Maritime Transport)

\begin{tabular}{|l|l|l|l|l|l|l|}
\hline $\begin{array}{l}\text { between reduce } \\
\text { working hours }\end{array}$ & .060 & .043 & .072 & 1.396 & .164 & \\
\hline $\begin{array}{l}\text { benefits } \\
\text { provided to } \\
\text { employees }\end{array}$ & .072 & .045 & .087 & 1.589 & .113 \\
\hline $\begin{array}{l}\text { work policies } \\
\text { towards } \\
\text { parenting }\end{array}$ & .219 & .052 & .236 & 4.175 & .000 \\
$\begin{array}{l}\text { Work-life } \\
\text { balance }\end{array}$ & .285 & .040 & .339 & 7.119 & .000 \\
\hline \multicolumn{2}{|l|}{ Dependent Variable: }
\end{tabular}

\section{VII.Testing the fifth Hypothesis}

Table 8 shows a regression analysis of the role of the mediator "gender" between work-life balance and Employee performance. Gender mediates the relationship between WLB and Employee performance, as its significance level for the interaction is less than 0.05 .

Table 8: Analyzing the role of the mediator "gender" between WLB and EP

\begin{tabular}{|c|c|c|c|c|c|c|}
\hline \multirow{2}{*}{ Variables } & \multicolumn{2}{|c|}{$\begin{array}{l}\text { Unstandardized } \\
\text { Coefficients }\end{array}$} & \multirow{2}{*}{$\begin{array}{l}\text { Standardiz } \\
\text { ed } \\
\text { Coefficients }\end{array}$} & \multirow[t]{2}{*}{$T$} & \multirow{2}{*}{ Sig. } & \multirow{2}{*}{$R 2$} \\
\hline & B & Std. & & & & \\
\hline (Constant) & 3.841 & .389 & & 9.880 & .000 & \multirow{5}{*}{0.3150} \\
\hline WLB & -.058 & .112 & -.069 & -.516 & .606 & \\
\hline gender & -1.335 & .302 & -.897 & 4.423 & .000 & \\
\hline WLB $*$ gender & .429 & .090 & 1.024 & 4.777 & .000 & \\
\hline \multicolumn{6}{|c|}{ a. Dependent Variable } & \\
\hline
\end{tabular}

Table 9 shows a regression analysis of the median role of "educational qualification" between life-work balance and Employee performance. The educational qualification does not mediate the relationship between life and work balance and Employee performance, as its significance level for the interaction is greater than 0.05 .

Table 9: Analyzing the role of the mediator "educational qualification" between WLB and EP

\begin{tabular}{|c|c|c|c|c|c|c|}
\hline \multirow{2}{*}{ Variables } & \multicolumn{2}{|c|}{$\begin{array}{l}\text { Unstandardized } \\
\text { Coefficients }\end{array}$} & \multirow{2}{*}{$\begin{array}{l}\text { Standardized } \\
\text { Coefficients }\end{array}$} & \multirow[t]{2}{*}{$T$} & \multirow[t]{2}{*}{ Sig. } & \multirow[t]{2}{*}{$R 2$} \\
\hline & $B$ & Std. & & & & \\
\hline (Constant) & 1.741 & .392 & & 4.441 & .000 & \multirow{4}{*}{0.283} \\
\hline WLB & .552 & .107 & .657 & 5.150 & .000 & \\
\hline $\begin{array}{l}\text { educational } \\
\text { qualification }\end{array}$ & .181 & .137 & .293 & 1.321 & .187 & \\
\hline $\begin{array}{l}\text { WLB*educational } \\
\text { qualification }\end{array}$ & -.037 & .038 & -.225 & -.971 & .332 & \\
\hline
\end{tabular}

Table10: a regression analysis of the median role of "years of experience" WLB and EP.

\begin{tabular}{|l|l|l|l|l|l|l|}
\hline \multirow{2}{*}{ Variables } & \multicolumn{2}{|l|}{$\begin{array}{l}\text { Unstandardized } \\
\text { Coefficients }\end{array}$} & $\begin{array}{l}\text { Standardized } \\
\text { Coefficients }\end{array}$ & $\boldsymbol{T}$ & Sig. & \multirow{2}{*}{ R2 } \\
\cline { 2 - 7 } & $\boldsymbol{B}$ & Std. Error & & 9.777 & .000 & \\
\hline (Constant) & 4.465 & .457 & & 957 \\
\hline
\end{tabular}


Flexible Work Arrangements and Their Impact on the Employee Performance of Egyptian Private University Employees: (A Case Study on the Arab Academy for Science, Technology, and Maritime Transport)

\begin{tabular}{|c|c|c|c|c|c|c|}
\hline WLB & -.126 & .125 & -.150 & \begin{tabular}{|l}
-1.009 \\
\end{tabular} & .313 & 0.3170 \\
\hline $\begin{array}{cc}\text { years } \\
\text { experience }\end{array}$ & $\begin{array}{l}-.663 \\
\end{array}$ & .133 & -1.041 & \begin{tabular}{|l}
-4.982 \\
\end{tabular} & .000 & \\
\hline $\begin{array}{l}\text { WLB* years of } \\
\text { experience }\end{array}$ & .171 & .037 & 1.171 & 4.693 & .000 & \\
\hline
\end{tabular}

Table 10 shows a regression analysis of the median role of "years of experience" between life and work balance and Employee performance. Years of experience mediate the relationship between work-life balance and Employee performance as the significance level of the interaction is less than 0.05 .

Table 11 shows a regression analysis of the role of the mediator "social status" between life-work balance and Employee performance. Marital status mediates the relationship between work-life balance and Employee performance, as its significance level for the interaction is less than 0.05 .

Table 11: a regression analysis of the role of the mediator "social status" between WLB and EP

\begin{tabular}{|c|c|c|c|c|c|c|}
\hline \multirow{2}{*}{ Variables } & \multicolumn{2}{|c|}{$\begin{array}{l}\text { Unstandardized } \\
\text { Coefficients }\end{array}$} & \multirow{2}{*}{$\begin{array}{l}\text { Standardized } \\
\text { Coefficients }\end{array}$} & \multirow{2}{*}{$T$} & \multirow{2}{*}{ Sig. } & \multirow{2}{*}{$R 2$} \\
\hline & $B$ & $\begin{array}{l}\text { Std. } \\
\text { Error }\end{array}$ & & & & \\
\hline (Constant) & 4.400 & .468 & & 9.398 & .000 & \multirow{5}{*}{0.312} \\
\hline WLB & -.180 & .138 & -.214 & -1.301 & .194 & \\
\hline social status & -1.000 & .212 & -.874 & -4.718 & .000 & \\
\hline $\begin{array}{c}\text { WLB* } \\
\text { social status }\end{array}$ & .294 & .064 & 1.022 & 4.587 & .000 & \\
\hline \multicolumn{6}{|l|}{ a. Depend } & \\
\hline
\end{tabular}

Table 12 shows a regression analysis of the role of the mediator "number of family members" between life and work balance and Employee performance. The number of family members mediates the relationship between work-life balance and Employee performance, as its significance level for the interaction is less than 0.05 .

Table 12: Analysis of the role of the mediator " number of family members" between WLB and EP

\begin{tabular}{|c|c|c|c|c|c|c|}
\hline \multirow{2}{*}{ Variables } & \multicolumn{2}{|c|}{$\begin{array}{l}\text { Unstandardized } \\
\text { Coefficients }\end{array}$} & \multirow{2}{*}{$\begin{array}{l}\text { Standardized } \\
\text { Coefficients }\end{array}$} & \multirow{2}{*}{$T$} & \multirow{2}{*}{ Sig. } & \multirow{2}{*}{$R 2$} \\
\hline & B & $\begin{array}{l}\text { Std. } \\
\text { Error }\end{array}$ & & & & \\
\hline (Constant) & 4.400 & .468 & & 9.398 & .000 & \multirow{4}{*}{0.291} \\
\hline WLB & -.180 & .138 & -.214 & -1.301 & .194 & \\
\hline $\begin{array}{l}\text { number of family } \\
\text { members }\end{array}$ & -1.000 & .212 & -.874 & -4.718 & .000 & \\
\hline $\begin{array}{l}\text { WLB* number of } \\
\text { family members }\end{array}$ & .294 & .064 & 1.022 & 4.587 & .000 & \\
\hline
\end{tabular}

Table 13 shows the regression analysis of the role of the mediator "age" between work-life balance and Employee performance. Age mediates the relationship between work and private life balance and Employee performance as its significance level values for the interaction are less than 0.05 . 
Flexible Work Arrangements and Their Impact on the Employee Performance of Egyptian Private University Employees: (A Case Study on the Arab Academy for Science, Technology, and Maritime Transport)

Table 13: Analysis of the role of the mediator "age" between WLB and EP

\begin{tabular}{|c|c|c|c|c|c|c|}
\hline \multirow{2}{*}{ Variables } & \multicolumn{2}{|c|}{$\begin{array}{l}\text { Unstandardized } \\
\text { Coefficients }\end{array}$} & \multirow{2}{*}{$\begin{array}{l}\text { Standardized } \\
\text { Coefficients }\end{array}$} & \multirow{2}{*}{$T$} & \multirow{2}{*}{ Sig. } & \multirow{2}{*}{$R 2$} \\
\hline & $\boldsymbol{B}$ & $\begin{array}{l}\text { Std. } \\
\text { Error }\end{array}$ & & & & \\
\hline (Constant) & 4.192 & .443 & & 9.454 & .000 & \\
\hline WLB & -.055 & .120 & -.065 & -.456 & .649 & \\
\hline age & .168 & .039 & 1.042 & 4.289 & .000 & \\
\hline WLB* age & -.650 & .144 & -.935 & -4.507 & .000 & \\
\hline \multicolumn{6}{|c|}{ a. Dependent Variable } & \\
\hline
\end{tabular}

Based on the previous results, H5: "affects the demographic factors on the relationship between work-life balance, and Employee performance of employees in Egyptian private universities due to personal and functional variables (age, gender, marital status, educational qualification, number of family members)", is partially acceptable.

Table 14: Summary of the results of the study hypotheses

\begin{tabular}{|l|l|l|}
\hline Hypothesis & Explanation & Result \\
\hline H1 & $\begin{array}{l}\text { There is a statistically significant effect between } \\
\text { flexible work Arrangement and the employee } \\
\text { performance of employees in Egyptian private }\end{array}$ & Fully supported \\
\hline H2 & $\begin{array}{l}\text { There is a statistically significant effect between } \\
\text { flexible work Arrangement and work-life balance } \\
\text { for employees in Egyptian private universities. }\end{array}$ & Fully supported \\
\hline H3 & $\begin{array}{l}\text { There is a statistically significant effect between the } \\
\text { work-life balance and the employee performance of } \\
\text { employees in Egyptian private. universities }\end{array}$ & Fully supported \\
\hline H4 & $\begin{array}{l}\text { Work-life balance mediates the relationship between } \\
\text { flexible work Arrangement and employee } \\
\text { performance of employees in Egyptian private } \\
\text { universities, }\end{array}$ & partially supported \\
\hline H5 & $\begin{array}{l}\text { Demographic factors affect the relationship between } \\
\text { work-life balance, and employee performance of } \\
\text { employees in Egyptian private universities. }\end{array}$ & partially supported \\
\hline
\end{tabular}

\section{DISCUSSIONN AND CONCLUSION}

This section explains the research hypothesis and to what extent these hypotheses support prior studies and literature reviewed. Regarding the first hypothesis, H1, there is a statistically significant effect between flexible work arrangements and employees' performance. Analysis of SEM to show the impact of flexible work arrangements, including: reducing working hours, benefits provided to employees, and work policies towards parenting, on employee performance showed that there is no significant effect of reducing working hours on employee performance, as the significance level is greater than 0.05 . There is also a significant positive impact of the benefits provided to employees on employee performance, as the significance level is less than 0.05 and the value of the estimation factor is greater than zero. Finally, there is a significant positive impact of work policies towards parenting on employee performance, as the significance level is less than 0.05 and the value of the coefficient of estimates is greater than zero. Based on the previous results, it can be noted that the first hypothesis, which is "there is a statistically significant effect between flexible work arrangements and employee performance," is fully supported. Regarding the second hypothesis H2:There is a 


\section{Flexible Work Arrangements and Their Impact on the Employee Performance of Egyptian Private University Employees: (A Case Study on the Arab Academy for Science, Technology, and Maritime Transport)}

statistically significant effect between flexible work arrangements and the working life balance of employees. It was found from the analysis of the structural equation model to show the impact of flexible work arrangements, including: (reduce working hours, benefits provided to employees and work policies towards parenting) on life and work balance, that there is no significant effect of reduce working hours on life and work balance, as the level of significance greater than 0.05 . While there is a significant positive impact of the benefits provided to employees on the work-life balance, as the significance level is less than 0.05 and the value of the estimate coefficient is greater than zero. Also, there is no significant effect of work policies towards parenting on work-life balance, as the significance level is greater than 0.05 .

Based on the previous results, it can be noted that the second hypothesis, which is "there is a statistically significant effect between flexible work arrangements and work-life balance," is fully supported. Regarding the third hypothesis, H3, thereis a statistically significant effect between work-life balance and employee performance. It was found from the analysis of the structural equation model to show the impact of work-life balance on employee performance that there is a positive and significant effect of work-life balance on employee performance, as the significance level is less than 0.05 and the value of the estimate's coefficient is greater than zero. Based on the previous results, it can be noted that the third hypothesis, which is "there is a statistically significant effect between work-life balance and employee performance," is fully supported. Regarding the fourth hypothesis, H4: WLB mediates the relationship between FWAs and EP, the results of the multiple regression model testing of flexible work arrangements and employee performance were found to be significant. It can also be noted that there is a significant effect of work-life balance on employee performance. Therefore, work-life balance can play a mediating role between flexible work arrangements and employee performance, as there is a direct relationship between them and employee performance. It can be noted that "work-life balance mediates the relationship between reduced working hours, work policies towards parenting, and employee performance" in part. Whereas "work-life balance mediates the relationship between benefits provided to employees and employee performance," it is partially supported. Based on the previous results, it can be noted that the fourth hypothesis, which is "work-life balance mediates the relationship between flexible work arrangements and employee performance," is partially supported.

Finally, regarding the fifth hypothesis, H5: Demographic factors affect the relationship between work-life balance and the performance of employees in Egyptian private universities due to personal and occupational variables (gender, age, marital status, educational qualification, number of family members, and years of experience).

The regression analysis of the role of the mediator "gender" between work-life balance and employee performance proved that gender mediates the relationship between life-work balance and employee performance, as its significance level for the interaction is less than 0.05 . The regression analysis of the role of the mediator "age" between work-life balance and employee performance proved that age mediates the relationship between work-life balance and employee performance, as its significance level for the interaction is less than 0.05 .

The regression analysis of the role of the mediator "scientific qualification" between work-life balance and employee performance also proved that the academic qualification does not mediate the relationship between work-life balance and employee performance, as the value of the significance level of the interaction is greater than 0.05 . While the regression analysis of the role of the mediator "years of experience" between work-life balance and employee performance proved that one year of experience mediates the relationship between work-life balance and employee performance, as its significance level for the interaction is less than 0.05 . The regression analysis of the role of the mediator "social status" between life and WLB and EP proved that the social situation mediates the relationship between WLB and EP, as its significance level for the interaction is less than 0.05. Finally, the regression analysis of the role of the mediator "number of family members" between WLB and EP proved that the number of family members mediates the relationship WLB and EP, as its significance level for the interaction is less than 0.05 .

Based on the previous results, it can be noted that the fifth hypothesis, which is "demographic factors affect the relationship between work-life balance and the employee performance of employees in Egyptian private universities," is partially supported.

\section{LIMITATION, RECOMMENDATIONS, AND SUGGESTIONS FOR FUTURE RESEARCH}

There are some methodological and theoretical limitations to this study that I must admit, which sometimes hinder the ability to generalize. The study also had time limits, the scope of the sample, as the data collected for the study included a limited period, and the study was conducted in one of the private universities without the other universities, and the research was satisfied with studying some variables and ignoring other variables that may have a greater impact on work-life balance. The researcher suggests conducting a study to measure the effect of reducing working hours on employees' performance or institutional performance. Specialists call for a global conference in which the laws of the International Labor Organization are discussed and work on their development. Provide flexible work policies as one of the important strategies provided by the Human Resources Department, which increases the competitive advantage, and helps in attracting high-quality employees who seek more flexibility in their work schedules, especially those wishing to work part-time. Flexible work arrangements are considered as a need for work and life, not something that an institution can offer to some and deprive them of other employees or provided by one organisation without another. The 
Flexible Work Arrangements and Their Impact on the Employee Performance of Egyptian Private University
Employees: (A Case Study on the Arab Academy for Science, Technology, and Maritime Transport)

researcher also recommends Arab researchers to pay attention to conducting future studies that deal with the framework used in this study.

\section{REFERENCE}

1) Adnan, Bataineh, K., 2019. Impact of work-life balance, happiness at work, on employee performance. International Business Research, 12(2), pp.99-112.

2) Ajayaghosh, D., \& Thampi, S. P. (2020). Work Life Balance as a Tool to Predict Employee Performance in Select Commercial Banks in Kerala. Our Heritage, vol. 68 issue1, 9252-9269.

3) Baeza, M. A., Gonzalez, J. A., \& Wang, Y. (2018). Job flexibility and job satisfaction among Mexican professionals: A socio-cultural explanation. Employee Relations, 40, 921-942. doi:10.1108/ER-12-2016-0236

4) Bear, k. (2017). The Relationship Between Perceptions and Actual Use of Workplace Flexibility and Employee Engagement. Master's Theses,4787, San Jose State University, USA.

5) Carnevale, J.B. and Hatak, I., 2020. Employee adjustment and well-being in the era of COVID-19: Implications for human resource management. Journal of Business Research, 116, pp.183-187.

6) Choo, J. L., Desa, N., \& Abu Hassan Asaari, M. (2016). http://sass.sciedupress.com Studies in Asian Social Science Vol. 3, No. 1; 2016 Published by Sciedu Press 21 ISSN 233Flexible Working Arrangement toward Organizational Commitment and Work-Family Conflict. Studies in Asian Social Science, 21-36.

7) Chung, H., \& Der Lippe, T. (2018). Flexible Working, Work-Life Balance, and Gender Equality. Social Indicators Research, 1-17.

8) De Sivatte, I., Gordon, J.R., Rojo, P. and Olmos, R., (2015). The impact of work-life culture on organizational productivity. Personnel Review.

9) Deepika, S., \& ELANGO, S. (2020). Work Life Balance-The Need of The Hour. Our Heritage, 68(1), 7236-7242.

10) Ghanem, Abdelnasser, (2010)." Acritical of work-Family Conflict Among Egyptian Academics” (A Case Study), Nottingham Trent University and Southampton Solent University, U.K.

11) Giovanis, E. (2018). The relationship between flexible employment arrangements and workplace performance in Great Britain. International Journal of Manpower, 51-70.

12) Govender, L., Migiro, S.O. and Kyule, A.K., (2018). Flexible work arrangements, job satisfaction and performance. Journal of Economics and Behavioral Studies, $10(3(\mathrm{~J}))$, pp.268-277.

13) Haider, M. and Azmi, F.T. (2019). A Review of Literature Work Life Balance and Job Satisfaction Journal of General Management Research, Vol. 6, Issue 1, pp. 65-77.

14) Hsu, Y.Y., Bai, C.H., Yang, C.M., Huang, Y.C., Lin, T.T. and Lin, C.H., 2019. Long hours' effects on work-life balance and satisfaction. BioMed Research International, 2019.

15) International Labour Organization, (2019). International Laboure Organization, ILO Working Conditions Laws Database, International Laboure Organization, Geneva (2017).

16) Ko, E. J., \& Kim, S. S. (2018). Intention to use flexible work arrangements: The case of workers in Korea and gender differences in motivation. Journal of Organizational Change Management, 31, 1438-1460. doi:10.1108/JOCM-01-20180001

17) Martínez-León, I.M., Olmedo-Cifuentes, I. and Sanchez-Vidal, M.E., (2019). Relationship between availability of WLB practices and financial results. Personnel Review.

18) Mendis, M.D.V.S. and Weerakkody, W.A.S., 2017. The impact of work life balance on employee performance with reference to telecommunication industry in Sri Lanka: a mediation model. Kelaniya Journal of Human Resource Management, 12(1), pp.72-100.

19) Obiageli, O.L., Uzochukwu, O.C. and Ngozi, C.D., (2015). Work-life balance and employee performance in selected commercial banks in Lagos State. European journal of research and reflection in management sciences, 3(4).

20) Semlali, S., \& Hassi, A. (2016). "Work-life balance: how can we help women IT professionals in Morocco?". Journal of Global Responsibility, 7(2), 210-225. https://doi.org/10.1108/JGR-07-2016-0017

21) Talukder, A.K.M., Vickers, M. and Khan, A. (2018), "Supervisor support and work-life balance: Impacts on Employee performance in the Australian financial sector", Personnel Review, Vol. 47 No. 3, pp. 727-744. https://doi.org/10.1108/PR12-2016-0314

22) Taşdelen-Karçkay, A. and Bakalım, O., 2017. The mediating effect of work-life balance on the relationship between workfamily conflict and life satisfaction. Australian Journal of Career Development, 26(1), pp.3-13.

23) Wells-Lepley, M., Thelen, L. A., \& Swanberg, J. (2015). Supervisors' use of flexibility as a strategic management tool: Prevalence and predictors. The Psychologist-Manager Journal, 18(1), 31-53. 
Flexible Work Arrangements and Their Impact on the Employee Performance of Egyptian Private University Employees: (A Case Study on the Arab Academy for Science, Technology, and Maritime Transport)

24) Wong, K., Chan, A.H. and Teh, P.L., 2020. How is work-life balance arrangement associated with organizational performance? A meta-analysis. International journal of environmental research and public health, 17(12), p.4446.

\section{I.Arabic references (translated):}

25) University of Minnesota, International Labor Organization Conventions, Human Rights Library, available at: http://hrlibrary.umn.edu/arabic/ilo.html, Last visit: August 20, 2021.

26) Al-Biyari, Samar Saeed, (2018), "The quality of work life and its impact on the organizational commitment of the employees of the Ministries of Labor and Social Development in the Gaza Strip", (unpublished master's thesis), Islamic University, Palestine.

27) Kharashi, Faisal (2019). The effectiveness of the Employee performance of human resources management and its role in achieving the outstanding performance of individuals in the sports institution (a field study in the Directorate of Youth and Sports of the State of M'sila), University of Mohamed Boudiaf, M'sila, Algeria.

28) Al-Buhairi, Hisham Mohamed Sabry, (2018). An analytical study of the impact of applying strategies to achieve work-life balance on the effectiveness of administrative performance of managers in government service institutions in Egypt. The Scientific Journal of Business and Environmental Studies, Volume IX (Second Issue). 